Research Article

www.ijrap.net

\title{
ANTIMICROBIAL ACTION OF DHUPANA (FUMIGATION WITH HERBS) WITH RESPECT TO AIR BORNE MICROBES IN INDOOR ENVIRONMENT OF CENTRAL HOSPITAL
}

\author{
Nisha Kumari ${ }^{* 1}$, Shashirekha ${ }^{2}$
}

${ }^{1}$ Associate professor Department of Roga Nidana, SDM Ayurveda College and Hospital Hassan, India

${ }^{2}$ Microbiologist SDM Ayurveda College and Hospital Hassan, India

Received on: 29/07/16 Revised on: 18/08/16 Accepted on: 20/09/16

\author{
*Corresponding author \\ E-mail: nishaathikary@rediffmail.com
}

DOI: 10.7897/2277-4343.075194

\begin{abstract}
Hospital has been the prone area for all kinds of organisms entering through different kind of patient who carry different infective organism. Patients, patient by standard, hospital employees, visitors and other healthy volunteers are at risk of developing infections through transmissions. Therefore an effective fumigation as disinfectant is essential to kill the airborne microbes effectively. Herbal fumigation is been carried out to detect the antimicrobial action in indoor hospital environment. Air sample was collected from reception, wards, and corridors by Hi media open petriplate exposure method and microbes were identified. The same area is subjected to herbal fumigation for stipulated period of time. Then again air sample has been collected from the same area where herbal fumigation was done. The effectiveness of herbal fumigation in its antimicrobial action was concluded after comparing before and after fumigation growth in the petriplate.
\end{abstract}

Key words: Dhupana, Antimicrobial, Haridra, Lashuna, Sarshapa, Nimba, Kaidarya, Tulsi, Chakrikas, Potato Dextrose Agar, Nutrient Agar

\section{INTRODUCTION}

Germicidal, antimicrobial, anti helmenthic property of garlic, tulsi, neem, turmeric, mustard, curry leaves are explained in detailed in Ayurvedic classics ${ }^{1}$. All these are natural and easily available common herbs. Phytochemical analysis of fresh and dried leaf extracts of Ocimum gratissimum ${ }^{2}$ revealed presence of antimicrobial principles such as resins, tannins, glycosides, alkaloids, flavonoids saponin, anthraquinone, cardiac glycoside, steroidal ring, steroidal trepans and carbohydrates at different concentrations. Ayurvedic texts categorise Tulsi as stimulant, aromatic and antipyretic ${ }^{3}$.

Ancient science has very clearly emphasized importance of sterile atmosphere in neonatal care unit, post natal care unit, Operation Theater and so on. In this regards it is an attempt to understand the utility of herbs such as Garlic, Turmeric, Mustard seeds, Curry leaves, Neem and Tulasi with the help of modern parameters. Ancient Acharyas have explained about these herbs as Krimighna individually ${ }^{4-8}$. Now as a combination in the form of fumigation how effective above drugs prove as krimighna which means to destroy worms and germs including sookshmakrimi which means microbes, was carried out in this work.

Since ancient time, naturally occurring plants have played an important role in the discovery of new therapeutic agents. Almost all antibiotics are subjected to the problem of bacterial resistance. Therefore, newer herbal antibacterial compounds from plants and their semisynthetic derivatives to overcome the resistance are under investigation. Garlic (Allium sativum Linn.) has an important dietary and medicinal role for centuries. Its therapeutic uses include beneficial effects on the cardiovascular system, antibiotic, anticancer, anti-inflammatory, hypoglycemic, and hormone-like effects Garlic extracts have been used to treat infections for thousands of years.
Pathogenic Microorganisms, insects and pests, are major obstacles of health in living area, densely populated and sensitive working areas like hospitals, clinical laboratories contain enormous pathogens which cause iatrogenic disease. The indoor environment of hospitals acts as a reservoir for opportunistic human pathogens people with decreased immune competence may be susceptible to normally harmless environmental microbes. This proportion of population with increased susceptibility is expanding rapidly. The diversity of microbial species associated with infections is also growing. Besides well-known nosocomial agents such as Candida albicans, Staphylococcus aureus, Pseudomonas aeruginosa and Aspergillus fumigates are emerging as causative agents ${ }^{9,10}$.

\section{MATERIALS AND METHOD}

Materials for dhupana: Raw herbs mentioned below, grinder, mould, cloth for drying, sunlight, burning charcoal, mud pot, ghee.

Materials for Microbial Study: Air sample of hospital, Petriplates, Chemicals and reagents to prepare agar medium, Incubators, Stains for coloring the smear, Glass slides, Compound Microscopes.

\section{Method}

The Air Sample collection of indoor environment of central hospital is collected before and after dhupana by Passive Open Air Petri Plate Exposure Method, the smear will be stained by Gram Stain method

The materials used for fumigation are as follows

- Sarshapa (Brassica Campestris) : Seeds

- Lashuna (Allium Sativum): Cloves

- Kaidarya (Murraya koenigiilinn.)/spreng: Leaves (Bergerakoenigii.spreng)

- Nimba (AzadirachtaIndica Linn) : Leaves

- Haridra (Curcuma Longa) : Rhizome

- Tulsi (Ocimum Sanctum) : Leaves 

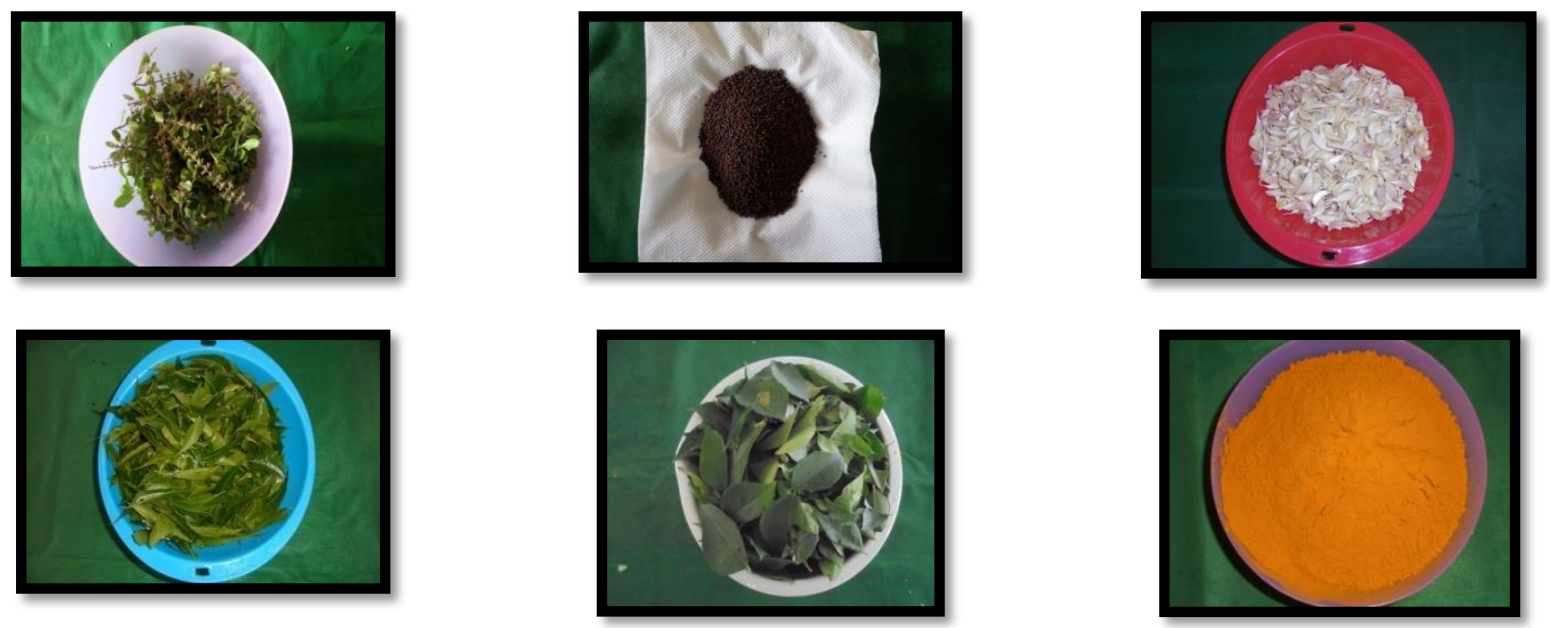

Picture 1

\section{Method of drug preparation}

Above mentioned drugs are washed in clean water under aseptic condition. Then each the drug were crushed separately and then mixed and made into a fine paste. Then it is made into Chakrika (herbal cookies) of equal size weighing about 5 gram each. Then it is dried in the sunlight for 5 days.
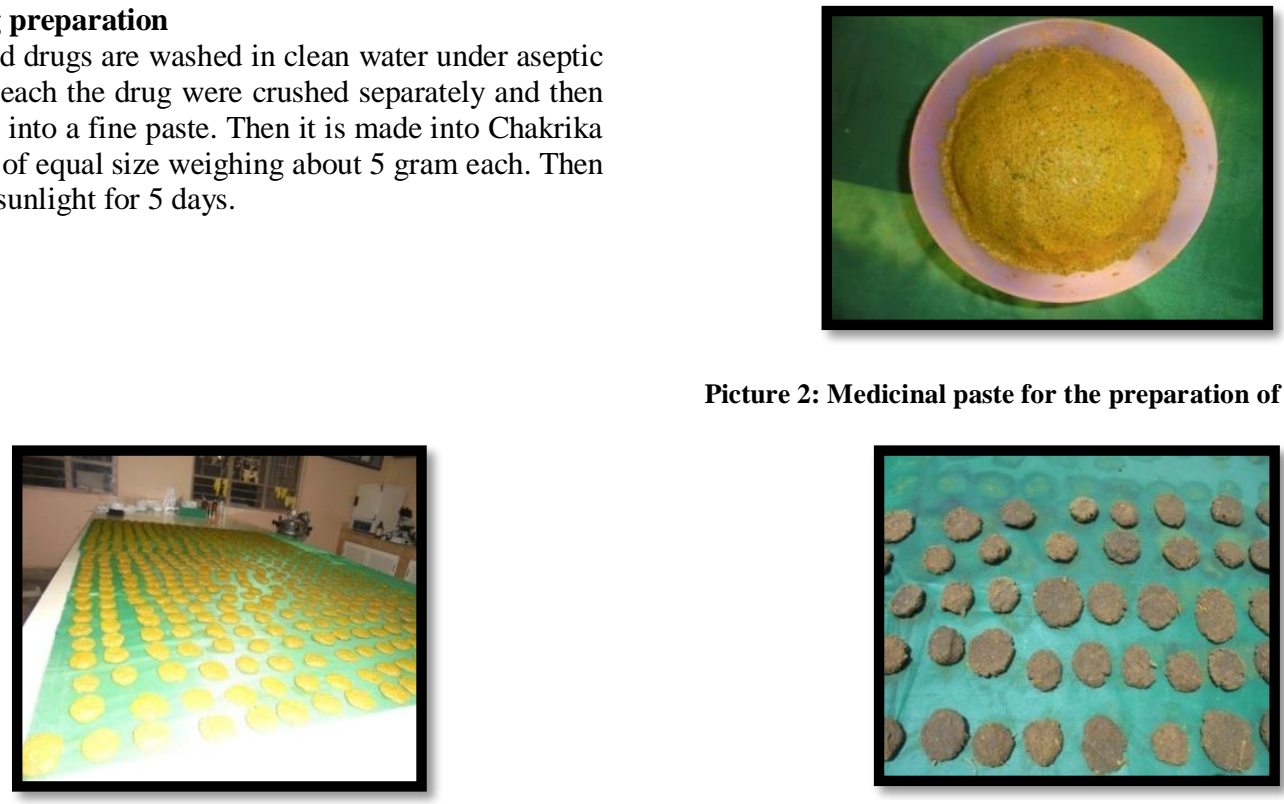

Picture 2: Medicinal paste for the preparation of Chakrikas

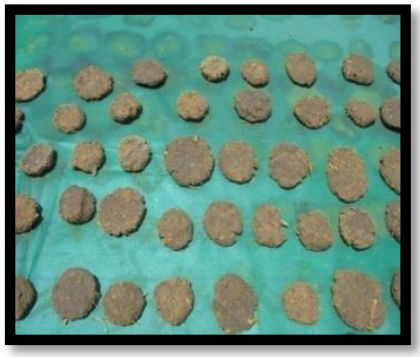

Picture 3: Drying of the Chakrikas

\section{Microbiological Study}

Preparation of Culture Media

Hi-Media was used for the preparation of culture media. This was prepared as per the classical method of media preparation by using Hi-media like Nutrient agar, Potato dextrose agar for Aerobic and Thioglycolate culture media for Anaerobic Microorganisms. After dissolving in distilled water with preferred amount of culture media this was autoclaved for 15 minutes for $15 \mathrm{lbs}$ pressure at $121{ }^{\circ} \mathrm{C}$. After autoclaving sterile petriplates was poured with $15 \mathrm{ml}$ of Hi-media preparation in an aseptic condition, and leave it for solidification. After solidification it was stored in refrigerator at $-2{ }^{\circ} \mathrm{C}[4-5,75]$ and used for the Passive monitoring. The petri plate is opened and exposed to the area desired and the organisms in the air gets trapped in the media. After sample collection from indoor hospital environment by Passive monitoring (Air exposure method \& Swabbing techniques) first herbal Fumigation (dhupana) would be done at $9.05 \mathrm{am}$,
It was done in the Shree Dharmasthala Manjunathaeshwara Ayurveda College and hospital campus. Three places were selected namely Entry of Hospital (Dhanwantari Statue and Reception area), IPD Wards (Male General Ward -2) and the Ward Corridors. Then the petri plates were exposed to the air at three respective locations as given above for 20 minutes.

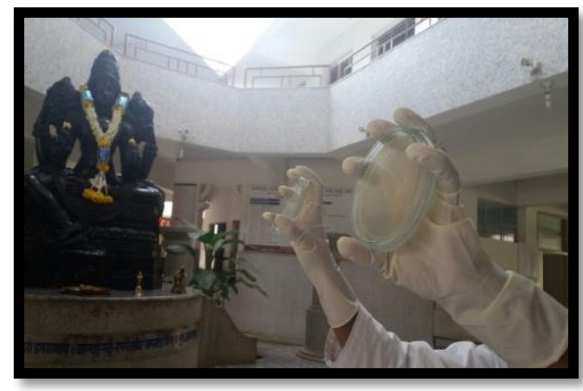

Picture 4: Air collection by Passive Open air Petri plate Exposure Method 
Organisms found after Petri plate Exposure in the Reception area are Bacteria and Fungi as follows:

- Staphylococcus aureus

- Pneumococcus.sps

- Pseudomonas.sps

- Acinetobacter.sps

- Penicillium.sps

- Aspergillus.sps

\section{Method of drug fumigation}

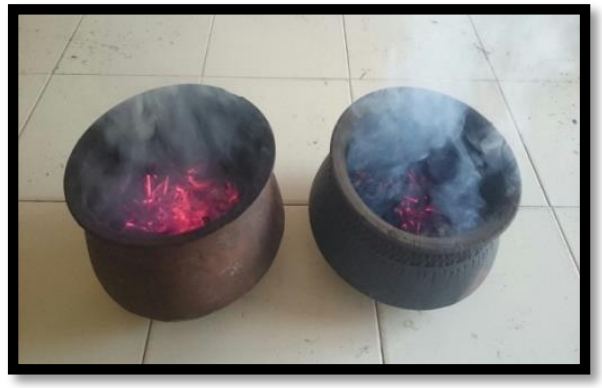

Picture 5: Dhupana (Herbal Fumigation)
The herbal cookies or dried chakrikas prepared are now crushed and sprinkled to burning charcoal. Soon they start to emit fumes. These fumes are allowed to spread in the area of collection of air sample. This is called as dhupana or herbal fumigation. After 15 minutes of dhupana 30 more minutes of duration is given for germicidal action. Second air sample for microbes was collected 30 minutes after completion of Fumigation. This second sample from the same place was taken by Passive monitoring method. The sample specimen is incubated at $37{ }^{\circ} \mathrm{C}$ for 24 hours in incubator for Aerobic Bacteria, Identification and characterization of Microorganisms were done for Microorganisms that are seen after Fumigation.

\section{Isolation of Airborne Bacteria}

Isolation of bacteria was done in the Shree Dharmasthala Manjunatheshwara Ayurveda College and Hospital campus. Three places were selected namely Entry of hospital, IPD Wards and the Corridors. To isolate the bacterial colonies Nutrient Agar for Bacteria and Potato Dextrose Agar for Fungi are used. Then the petri plates were exposed to the air at three respective locations as given above for 20 minutes. Now the Nutrient Agar plates were kept in the incubator at $37{ }^{\circ} \mathrm{C}$ For 24 hours and Potato Dextrose Agar plates in room temperature for 48-72 hours. Now after incubation, distinct bacterial and fungal colonies are observed.

Table 1: Procedure for Fumigation and Sample collection

\begin{tabular}{|l|l|l|}
\hline Number of Samples And Fumigation & Morning At 9.00am & Evening At 5.00pm \\
\hline Sample 1 & Culture media Exposure for 2minutes & Culture media exposure for 2 minutes \\
\hline Fumigation with Dhupanadravyas & Fumigation for 15 min & Fumigation for 15 min \\
\hline Sample 2 & $\begin{array}{l}\text { Hi-Media Exposed to air For 2 minutes after } \\
\text { Fumigation at 9.20am }\end{array}$ & $\begin{array}{l}\text { Hi-Media Exposed to air For 2 minutes } \\
\text { after Fumigation at 5.20pm }\end{array}$ \\
\hline Sample 3 & $\begin{array}{l}\text { Hi-Media Exposed to air For 2 minutes. 30minutes } \\
\text { after 2nd } \text { sample taken. That is at 9.50 am }\end{array}$ & $\begin{array}{l}\text { Hi-Media Exposed to air For 2 minutes. } \\
\text { After 30 minutes that is at 5.50pm }\end{array}$ \\
\hline Sample 4 & $\begin{array}{l}\text { Culture media Exposure for 2minutes after 30 } \\
\text { minutes at 10.20am }\end{array}$ & $\begin{array}{l}\text { Culture media Exposure for 2minutes after } \\
\text { 30 minutes at 6.20pm }\end{array}$ \\
\hline
\end{tabular}

\section{OBSERVATIONS}

Before and after Dhupana, exposure of Nutrient agar plates in Entrance (Reception area)

During the exposure of Nutrient Agar plate in the Entrance area for 2 minutes, it was observed that the medium showed medium to minimal growth of organisms in the plate after 24 hours of incubation in the incubator at $37^{\circ} \mathrm{C}$. Afterwards Dhupana has been done for 15 minutes in the same area. Once again the Nutrient Agar plate was exposed in the same area for 2 minutes after 15 minutes of fumigation. There observed very minimal organism growth after 24 hours of culturing in the incubatorat $37^{\circ} \mathrm{C}$.

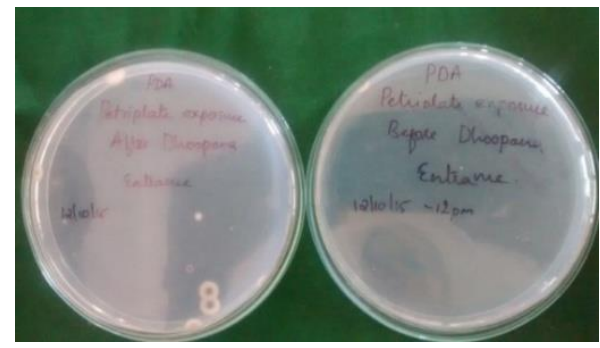

Picture 6: Before and after Dhupana, exposure of potato dextrose agar plates in Entrance (Reception area)

During the exposure of Potato Dextrose Agar plate in the Entrance area for 2 minutes, it was observed the medium to minimal growth of organisms in the plate after $48-72$ hours in the room temperature. Afterwards Dhupana has been done for 15 minutes in the same area. Once again the Potato Dextrose Agar plate was exposed in the same area for 2 minutes after 15 minutes of fumigation. There observed very minimal organism growth after 48-72 hours of culturing in the room temperature.

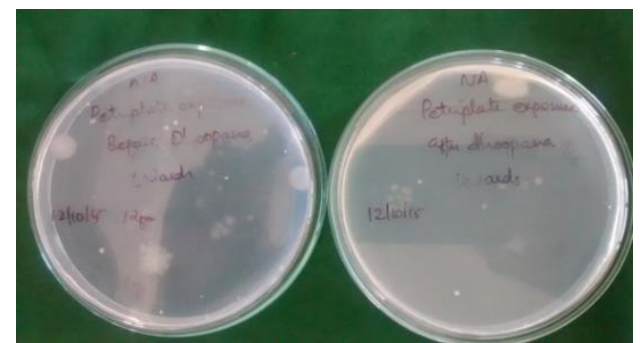

Picture 7: Before and After Dhupana, exposure of Nutrient agar plates in Ward (Male General Ward)

During the exposure of Nutrient Agar plate in the Male General Ward 2 for 2 minutes, it was observed the medium to minimal growth of organisms in the plate after 24 hours of incubation in the incubator at $37{ }^{\circ} \mathrm{C}$. Afterwards Dhupana has been done for 15 minutes in the same area. Once again the Nutrient Agar plate was exposed in the same area for 2 minutes after 15 minutes of fumigation. There observed very minimal organism growth after 24 hours of culturing in the incubator at $37{ }^{\circ} \mathrm{C}$. 


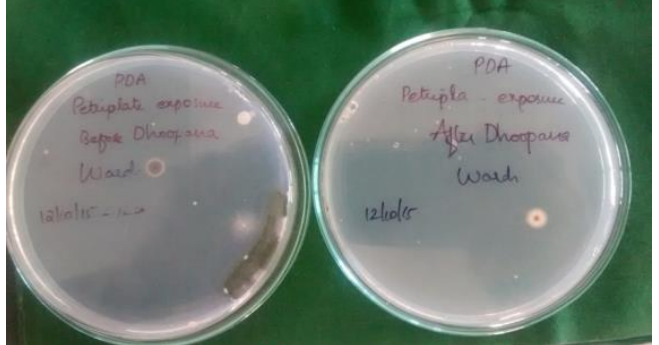

Picture 8: Before and After Dhupana, Exposure of potato dextrose agar plates in Ward

During the exposure of Potato Dextrose Agar plate in the Male General Ward 2 for 2 minutes, it was observed the medium to minimal growth of organisms in the plate after 48-72 hours of culturing in the room temperature. Afterwards Dhupana has been done for 15 minutes in the same area. Once again the Potato Dextrose Agar plate was exposed in the same area for 2 minutes after 15 minutes of fumigation. There observed very minimal organism growth after 48-72 hours of culturing in the room temperature.

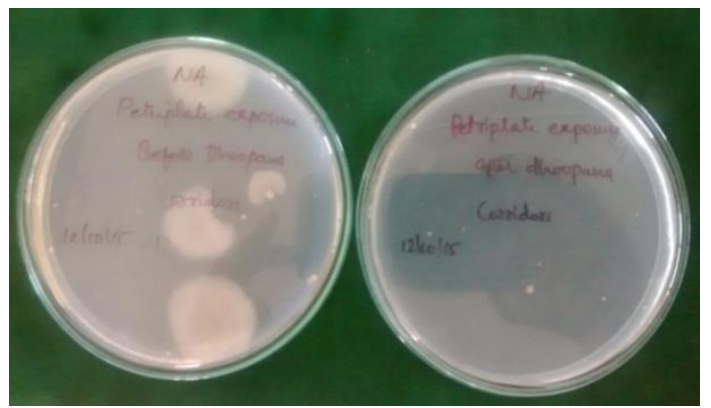

During the exposure of Nutrient Agar plate in the Corridor area of Wards for 2 minutes, it was observed the medium to minimal growth of organisms in the plate after 24 hours of incubation in the incubator at $37{ }^{\circ} \mathrm{C}$. Afterwards Dhupana has been done for 15 minutes in the same area. Once again the Nutrient Agar plate was exposed in the same area for 2 minutes after 5 minutes of fumigation. There observed very minimal organism growth after 24 hours of culturing in the incubator at $37^{\circ} \mathrm{C}$.

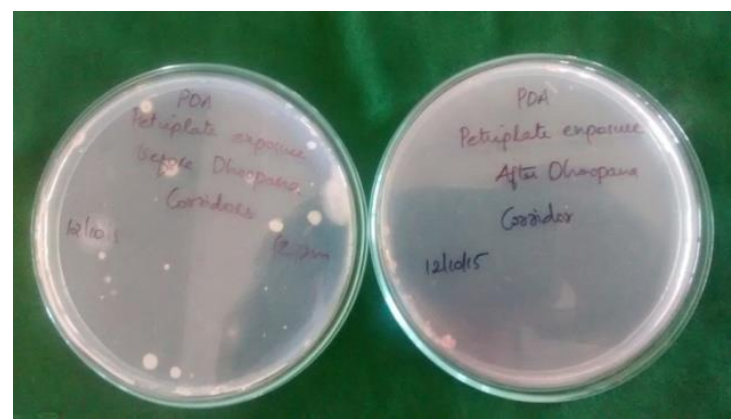

Picture 10: Before and After Dhupana, exposure of potato dextrose agar plates in Ward Corridors

During the exposure of Potato Dextrose Agar plate in the Corridor area of wards for 2 minutes, it was observed medium to minimal growth of organisms in the plate after 48-72hours of incubation in the room temperature. Afterwards Dhupana has been done for 15 minutes in the same area. Once again the Potato Dextrose Agar plate was exposed in the same area for 2 minutes after 15 minutes of fumigation. There observed very minimal organism growth after 48-72hours of incubation in the room temperature.

Picture 9: Before and After Dhupana, exposure of Nutrient agar plates in Ward Corridors

Table 2: Day I - Morning - Nutrient Agar plates

\begin{tabular}{|c|c|c|c|c|}
\hline Day & Before Dhupana-9.00Am & $\begin{array}{c}\text { After Dhupana - } \\
\text { 9.20Am \& 9.30Am }\end{array}$ & $\begin{array}{l}\text { After } 1 / 2 \text { an hour after Dhupana } \\
-9.50 \mathrm{Am} \& 10.05 \mathrm{Am}\end{array}$ & Micro organism \\
\hline Day I-Entrance & $\begin{array}{l}\text { Gram negative Bacilli, } \\
\text { Gram Positive Diplococci }\end{array}$ & Gram negative Bacilli, & Gram negative Bacilli & $\begin{array}{c}\text { E.coli, Pneumococci.sps, } \\
\text { Staphylococci,sps, } \\
\text { Actinomyces }\end{array}$ \\
\hline Day I - Corridor & $\begin{array}{c}\text { Gram positive Cocci Gram } \\
\text { negative bacilli }\end{array}$ & Gram positive Cocci & No growth & $\begin{array}{c}\text { Staphylococci,sps, } \\
\text { Actinomyces }\end{array}$ \\
\hline Day I - Ward & Gram negative Bacilli & Gram negative Bacilli & No growth & E.coli, Yersenia.sps \\
\hline
\end{tabular}

Table 3: Day I - Morning - Potato Dextrose plates

\begin{tabular}{|c|c|c|c|c|}
\hline Day & $\begin{array}{l}\text { Before Dhupana - } \\
9.00 \mathrm{Am}\end{array}$ & $\begin{array}{c}\text { After Dhupana - 9.20Am } \\
\& 9.30 \mathrm{Am}\end{array}$ & $\begin{array}{c}\text { After } 1 / 2 \text { an hour after Dhupana - } \\
\text { 9.50Am \& } 10.05 \mathrm{Am}\end{array}$ & Micro organism \\
\hline Day I-Entrance & Growth seen & Growth seen & Growth seen & $\begin{array}{c}\text { Rhizopus.sps, } \\
\text { Mucor.sps, } \\
\text { Aspergillus } \\
\text { fumigatus, } \\
\text { Penicillium.sps } \\
\end{array}$ \\
\hline Day I - Corridor & Growth seen & Growth seen & Growth seen & $\begin{array}{c}\text { Cladosporium.sps, } \\
\text { Mucor.sps, } \\
\text { Aspergillus fumigatus }\end{array}$ \\
\hline Day I - Ward & Growth seen & Growth seen & Growth seen & $\begin{array}{l}\text { Curvularia.sps, } \\
\text { Aspergillus.sps }\end{array}$ \\
\hline
\end{tabular}

Table 4: Day I - Evening - Nutrient Agar plates

\begin{tabular}{|c|c|c|c|c|}
\hline Day & Before Dhupana - 4.00Pm & $\begin{array}{c}\text { After Dhupana - } \\
4.25 \mathrm{Pm} \& 4.35 \mathrm{Pm}\end{array}$ & $\begin{array}{c}\text { After 1/2 an hour after Dhupana } \\
-4.40 \mathrm{Pm} \& 4.50 \mathrm{Pm}\end{array}$ & Micro organism \\
\hline Day I - Entrance & Gram negative Bacilli & No growth & Gram negative Bacilli & E.coli, Yersenia.sps \\
\hline Day I - Corridor & Gram positive cocci & No growth & Gram positive cocci & Staphylococci,sps, \\
\hline Day I - Ward & Gram negative Bacilli, & No growth & $\begin{array}{c}\text { Gram negative Bacilli, Gram } \\
\text { positive cocci }\end{array}$ & $\begin{array}{c}\text { Staphylococci,sps, } \\
\text { Pneumococci.sps, } \\
\text { E.coli }\end{array}$ \\
\hline
\end{tabular}


Table 5: Day I - Evening - Potato Dextrose plates

\begin{tabular}{|c|c|c|c|c|}
\hline Day & $\begin{array}{l}\text { Before Dhupana- } \\
4.00 \mathrm{Pm}\end{array}$ & $\begin{array}{l}\text { After Dhupana- } \\
4.25 \mathrm{Pm} \& 4.35 \mathrm{Pm}\end{array}$ & $\begin{array}{c}\text { After } 1 / 2 \text { an hour after Dhupana - } \\
4.40 \mathrm{Pm} \& 4.50 \mathrm{Pm}\end{array}$ & Micro organism \\
\hline Day I - Entrance & Growth seen & No growth & No growth & $\begin{array}{c}\text { Rhizopus.sps, } \\
\text { Mucor.sps, } \\
\text { Aspergillus } \\
\text { fumigatus, } \\
\text { Penicillium.sps }\end{array}$ \\
\hline Day I - Corridor & Growth seen & No growth & No growth & $\begin{array}{c}\text { Mucor.sps, } \\
\text { Aspergillus } \\
\text { fumigatus, } \\
\text { Cladosporium.sps } \\
\text { Rhizopus.sps }\end{array}$ \\
\hline Day I-Ward & Growth seen & No growth & No growth & $\begin{array}{c}\text { Aspergillus } \\
\text { fumigatus, } \\
\text { Curvularia.sps, } \\
\text { Penicillum.sps }\end{array}$ \\
\hline
\end{tabular}

Table 6: Day II - Morning - Nutrient Agar plates

\begin{tabular}{|c|c|c|c|c|}
\hline Day & $\begin{array}{c}\text { Before Dhupana - } \\
\text { 9.15Am }\end{array}$ & $\begin{array}{c}\text { After Dhupana } 9.50 \mathrm{Am} \mathrm{\&} \\
10.00 \mathrm{Am}\end{array}$ & $\begin{array}{c}\text { After } 1 / 2 \text { an hour after Dhupana } \\
-10.05 \mathrm{Am} \& 10.15 \mathrm{Am}\end{array}$ & Micro organism \\
\hline Day II - Entrance & Gram negative Bacilli, & $\begin{array}{l}\text { Gram PositiveDiplococci, } \\
\text { Gram Negative Bacilli }\end{array}$ & $\begin{array}{c}\text { Gram Positivecocci, Gram } \\
\text { Negative Bacilli, Gram } \\
\text { Positive Diplococci }\end{array}$ & $\begin{array}{l}\text { E.coli, Yersenia.sps } \\
\text { Staphylococci,sps, } \\
\text { Pneumococci.sps, } \\
\text { Actinomyces }\end{array}$ \\
\hline Day II - Corridor & Gram negative Bacilli & Gram Negative Bacilli & $\begin{array}{c}\text { Actinimyces, Gram Negative } \\
\text { Bacilli }\end{array}$ & $\begin{array}{l}\text { Aerobic spore } \\
\text { forming bacteria, } \\
\text { Yersenia.sps }\end{array}$ \\
\hline Day II - Ward & $\begin{array}{c}\text { Gram negative Bacilli, } \\
\text { Gram Positive } \\
\text { Diplococci }\end{array}$ & $\begin{array}{l}\text { Gram negative } \\
\text { Bacilli,Tetrad }\end{array}$ & Gram Negative Bacilli & $\begin{array}{l}\text { Yersenia.sps Aerobic } \\
\text { spore forming } \\
\text { bacteria, } \\
\text { staphylococci.sps }\end{array}$ \\
\hline
\end{tabular}

Table 7: Day II - Morning - Potato Dextrose plates

\begin{tabular}{|c|c|c|c|c|}
\hline Day & $\begin{array}{c}\text { Before Dhupana - } \\
\text { 9.15Am }\end{array}$ & $\begin{array}{c}\text { After Dhupana-9.50Am \& } \\
\text { 10.00Am }\end{array}$ & $\begin{array}{c}\text { After } 1 / 2 \text { an hour after Dhupana - } \\
10.05 \mathrm{Am} \& 10.15 \mathrm{Am}\end{array}$ & Micro organism \\
\hline Day II - Entrance & Growth seen & No growth & Growth seen & $\begin{array}{c}\text { Cladosporium.sps } \\
\text { Aspergillus } \\
\text { fumigatus, } \\
\text { Curvularia.sps, } \\
\text { Penicillum.sps }\end{array}$ \\
\hline Day II - Corridor & Growth seen & No growth & Growth seen & $\begin{array}{l}\text { Penicillium.sps, } \\
\text { Rhizopus.sps }\end{array}$ \\
\hline Day II - Ward & Growth seen & No growth & Growth seen & $\begin{array}{l}\text { Mucor.sps, } \\
\text { Aspergillus } \\
\text { fumigatus, } \\
\text { Rhizopus.sps }\end{array}$ \\
\hline
\end{tabular}

Table 8: Day II - Evening - Nutrient Agar plates

\begin{tabular}{|c|c|c|c|c|}
\hline Day & Before Dhupana - 4.10Pm & $\begin{array}{c}\text { After Dhupana - 4.35Pm } \\
\& 4.45 \mathrm{Pm}\end{array}$ & $\begin{array}{c}\text { After 1/2 an hour after } \\
\text { Dhupana-4.50pm \& 5.00Pm }\end{array}$ & $\begin{array}{c}\text { Micro organism } \\
\text { Day II - Entrance }\end{array}$ \\
$\begin{array}{c}\text { Gram Negative Bacilli, } \\
\text { Gram Positive Diplococci }\end{array}$ & No growth & $\begin{array}{c}\text { Gram negative bacteria, } \\
\text { Actinomyces, } \\
\text { Pneumococci.sps }\end{array}$ \\
\hline Day II - Corridor & Gram negative Bacilli & No Growth & Gram negative bacteria, & Actinomyces \\
\hline Day II - Ward & Gram Positive Diplococci & No Growth & $\begin{array}{c}\text { Gram negative bacilli, gram } \\
\text { positive diplococci }\end{array}$ & $\begin{array}{c}\text { Yersenia.sps } \\
\text { Pneumococci.sps, }\end{array}$ \\
\hline
\end{tabular}

Table 9: Day II - Evening - Potato Dextrose Agar plates

\begin{tabular}{|c|c|c|c|c|}
\hline Day & $\begin{array}{c}\text { Before Dhupana- } \\
4.10 \mathrm{Pm}\end{array}$ & $\begin{array}{c}\text { After Dhupana }-4.35 \mathrm{Pm} \\
\& 4.45 \mathrm{Pm}\end{array}$ & $\begin{array}{c}\text { After 1/2 an hour after } \\
\text { Dhupana-4.50pm \& 5.00Pm }\end{array}$ & $\begin{array}{c}\text { No growth } \\
\text { Rhizopus.sps, Mucor.sps, } \\
\text { Aspergillus fumigatus, }\end{array}$ \\
\hline Day II - Entrance & Growth seen & No growth & No growth & $\begin{array}{c}\text { Aspergillus fumigatus, } \\
\text { Penicillum.spscurvularia.sps }\end{array}$ \\
\hline Day II - Corridor & Growth seen & No growth & No growth \\
Cladosporium.sps \\
Aspergillus fumigatus
\end{tabular}


Table 10: Day III - Morning - Nutrient Agar plates

\begin{tabular}{|c|c|c|c|c|}
\hline Day & Before Dhupana- 9.10Am & $\begin{array}{c}\text { After Dhupana- } \\
9.50 \text { Am \& 10.00Am }\end{array}$ & $\begin{array}{c}\text { After 1/2 an hour after Dhupana } \\
-10.05 \text { Am \&10.15Am }\end{array}$ & Micro organism \\
\hline Day III - Entrance & Gram negative Bacilli, & No growth & No growth & Yersenia.sps \\
\hline Day III - Corridor & Gram Positive Diplococci & No Growth & $\begin{array}{c}\text { Gram negative Bacilli, } \\
\text { Streptobacilli }\end{array}$ & $\begin{array}{c}\text { Bacillus.sps } \\
\text { Yersenia.sps, }\end{array}$ \\
\hline Day III - Ward & $\begin{array}{c}\text { Gram Positive Diplococci, } \\
\text { Gram negative Bacilli, }\end{array}$ & No growth & $\begin{array}{c}\text { Gram negative Bacilli, } \\
\text { Streptobacilli }\end{array}$ & $\begin{array}{c}\text { Yersenia.sps } \\
\text { Bacillus.sps, } \\
\text { Pneumococci.sps, }\end{array}$ \\
\hline
\end{tabular}

Table 11: Day III - Morning - Potato Dextrose plates

\begin{tabular}{|c|c|c|c|c|}
\hline Day & $\begin{array}{c}\text { Before Dhupana- } \\
9.10 \mathrm{Am}\end{array}$ & $\begin{array}{c}\text { After Dhupana-9.50Am } \\
\& 10.00 \mathrm{Am}\end{array}$ & $\begin{array}{c}\text { After 1/2 an hour after Dhupana } \\
-10.05 \text { Am \& 10.15Am }\end{array}$ & $\begin{array}{c}\text { Micro organism } \\
\text { Growth seen }\end{array}$ \\
\hline Day III - Entrance & Growth seen & No growth & $\begin{array}{c}\text { Cladosporium.sps } \\
\text { Aspergillus fumigatus, } \\
\text { Penicillium.sps }\end{array}$ & $\begin{array}{c}\text { Curvularia.sps, } \\
\text { Penicillium.sps }\end{array}$ \\
\hline Day III - Corridor & Growth seen & No growth & Growth seen & $\begin{array}{c}\text { Aspergillus fumigatus, } \\
\text { Penicillum.spscurvularia.sps }\end{array}$ \\
\hline Day III - Ward & Growth seen & No growth & Growth seen &
\end{tabular}

Table 12: Day III - Evening - Nutrient Agar plates

\begin{tabular}{|c|c|c|c|c|}
\hline Day & Before Dhupana - 4.10Pm & $\begin{array}{l}\text { After Dhupana- } \\
4.35 \mathrm{pm} \& 4.45 \mathrm{Pm}\end{array}$ & $\begin{array}{c}\text { After } 1 / 2 \text { an hour after } \\
\text { Dhupana }-4.50 \mathrm{Pm} \& 5.00 \mathrm{Pm}\end{array}$ & Micro organism \\
\hline Day III - Entrance & $\begin{array}{l}\text { Gram Positive Diplococci, } \\
\text { Gram -ve bacteria }\end{array}$ & No growth & No growth & $\begin{array}{c}\text { Actinimyces, Tetrad, } \\
\text { Pneumococci.sps }\end{array}$ \\
\hline Day III - Corridor & $\begin{array}{l}\text { Gram Negative Bacilli, } \\
\text { Gram Positive Diplococci, }\end{array}$ & No growth & No growth & $\begin{array}{c}\text { Yersenia.sps, } \\
\text { Actinomyces.sps, } \\
\text { Pneumococci.sps }\end{array}$ \\
\hline Day III - Ward & $\begin{array}{c}\text { Gram Negative Bacilli, Gram } \\
\text { Positive, Diplococci, }\end{array}$ & No growth & No growth & $\begin{array}{l}\text { Pseudomonas.sps, } \\
\text { Pneumococci.sps }\end{array}$ \\
\hline
\end{tabular}

Table 13: Day III - Evening - Potato Dextrose Agar plates

\begin{tabular}{|c|c|c|c|c|}
\hline Day & $\begin{array}{c}\text { Before Dhupana- } \\
\text { 4.10Pm }\end{array}$ & $\begin{array}{c}\text { After Dhupana- } 4.35 \mathrm{pm} \\
\& 4.45 \mathrm{Pm}\end{array}$ & $\begin{array}{c}\text { After } 1 / 2 \text { an hour after } \\
\text { Dhupana- } 4.50 \mathrm{Pm} \& 5.00 \mathrm{Pm}\end{array}$ & Micro organism \\
\hline Day III - Entrance & Growth seen & No growth & No growth & $\begin{array}{c}\text { Aspergillus } \\
\text { fumigatus, } \\
\text { Cladosporium.sps } \\
\text { Penicillum. } \\
\text { spscurvularia.sps }\end{array}$ \\
\hline Day III - Corridor & Growth seen & No growth & No growth & $\begin{array}{l}\text { Penicillium.sps, } \\
\text { Aspergillus nigar }\end{array}$ \\
\hline Day III - Ward & Growth seen & No growth & No growth & $\begin{array}{c}\text { Aspergillus } \\
\text { fumigatus, } \\
\text { Rhizopus.sps }\end{array}$ \\
\hline
\end{tabular}

Table 14: Day IV - Morning - Nutrient Agar plates

\begin{tabular}{|c|c|c|c|}
\hline Day & Before Dhupana - 9.10Am & After Dhupana - 9.45Am \& 9.45Pm & Micro organism \\
\hline Day IV - Entrance & $\begin{array}{c}\text { Gram positive diplococcic, gram } \\
\text { negative bacilli }\end{array}$ & No growth & $\begin{array}{c}\text { Aerobic spore forming } \\
\text { bacteria, Pseudomonas.sps, } \\
\text { Pneumococci.sps }\end{array}$ \\
\hline Day IV - Corridor & Gram positive cocci.gram positive & & $\begin{array}{c}\text { Staphylococci.sps, } \\
\text { diplococci }\end{array}$ \\
\hline Day IV - Ward & Gram positive diplococci & No growth & Pneumococci.sps \\
\hline
\end{tabular}

Table 15: Day IV - Morning - Potato Dextrose plates

\begin{tabular}{|c|c|c|c|}
\hline Day & Before Dhupana - 9.10Am & After Dhupana-9.45Am \& 9.45Pm & Micro organism \\
\hline Day IV - Entrance & Growth seen & Growth seen & $\begin{array}{c}\text { Alternaria.sps, } \\
\text { Cladosporium.sps } \\
\text { Penicillium.sps, } \\
\text { Aspergillus.sps }\end{array}$ \\
& & & Aspergillus fumigatus, \\
& & Penicillum. \\
& & Growth seen & spscurvularia.sps \\
\hline Day IV - Corridor & Growth seen & Penicillium.sps, \\
& & Gspergillus.nigar \\
\hline
\end{tabular}

Table 16: Day IV - Evening - Nutrient Agar plates

\begin{tabular}{|c|c|c|c|}
\hline Day & Before Dhupana $-4.10 \mathrm{Pm}$ & After Dhupana- 4.35Pm \&4.45Pm & Micro organism \\
\hline Day IV - Entrance & $\begin{array}{c}\text { Artinomyces, } \\
\text { Pneumococci.sps }\end{array}$ & No growth \\
& diplocicci & No growth & Pneumococci.sps \\
\hline Day IV - Corridor & Gram positive diplococci, & No growth & Yersenia.sps, E.coli \\
\hline Day IV - Ward & Gram negative bacteria & & Prive \\
\hline
\end{tabular}


Table 17: Day IV - Evening - Potato Dextrose plates

\begin{tabular}{|c|c|c|c|}
\hline Day & Before Dhupana-4.10Pm & After Dhupana- 4.35Pm \& 4.45Pm & Micro organism \\
\hline Day IV - Entrance & Growth seen & No growth & $\begin{array}{c}\text { Aspergillus nigar, } \\
\text { Rhizopus.sps, Mucor.sps }\end{array}$ \\
\hline Day IV - Corridor & Growth seen & No growth & $\begin{array}{c}\text { Rhizopus.sps, Mucor.sps } \\
\text { Cladosporium.sps }\end{array}$ \\
\hline Day IV - Ward & Growth seen & No growth & $\begin{array}{c}\text { Penicillium.sps, } \\
\text { Aspergillus.nigar }\end{array}$ \\
\hline
\end{tabular}

Table 18: Day V - Morning - Nutrient Agar plates

\begin{tabular}{|c|c|c|c|}
\hline Day & Before Dhupana - 9.30Am & After Dhupana- 10.00Am \& 10.10Am & Micro organism \\
\hline Day V - Entrance & Gram negative bacilli & Gram negative bacilli & $\begin{array}{c}\text { Aerobic spore forming } \\
\text { bacteria }\end{array}$ \\
\hline Day V - Corridor & $\begin{array}{c}\text { Gram Negative Bacilli, Gram Positive, } \\
\text { Diplococci, }\end{array}$ & Gram positive Diplococci & $\begin{array}{c}\text { Pneumococci.sps, } \\
\text { aerobic spore forming } \\
\text { bacteria }\end{array}$ \\
\hline Day V - Ward & $\begin{array}{c}\text { Gram Positive Diplococci, Gram-ve } \\
\text { bacteria }\end{array}$ & Gram positive diplococci & $\begin{array}{c}\text { Yersenia.sps, } \\
\text { Pneumococci.sps }\end{array}$ \\
\hline
\end{tabular}

Table 19: Day V - Morning - Potato Dextrose plates

\begin{tabular}{|c|c|c|c|}
\hline Day & Before Dhupana -9.30Am & After Dhupana - 10.00Am \& 10.10Am & Micro organism \\
\hline Day V - Entrance & Growth seen & Growth seen & $\begin{array}{c}\text { Aspergillus.nigar, } \\
\text { Aspergillus.fumigatus, } \\
\text { Rhizopu.sps }\end{array}$ \\
\hline Day V - Corridor & Growth seen & $\begin{array}{c}\text { Aspergillus nigar, } \\
\text { Rhizopus.sps, Mucor.sps }\end{array}$ \\
\hline Day V-Ward & Growth seen & Growth seen & $\begin{array}{c}\text { Penicillium.sps, } \\
\text { Aspergillus.nigar }\end{array}$ \\
\hline
\end{tabular}

Table 20: Day V - Evening - Nutrient Agar plates

\begin{tabular}{|c|c|c|c|}
\hline Day & Before Dhupana $-4.20 \mathrm{Pm}$ & After Dhupana $-4.40 \mathrm{Pm} \& 4.50 \mathrm{Pm}$ & Micro organism \\
\hline Day V - Entrance & $\begin{array}{c}\text { Gram positive diplococci, gram negative } \\
\text { bacteria }\end{array}$ & No growth & $\begin{array}{c}\text { Pneumococci.sps, } \\
\text { aerobic spore forming } \\
\text { bacteria }\end{array}$ \\
\hline Day V - Corridor & Gram negative bacilli & $\begin{array}{c}\text { Aerobic spore forming } \\
\text { bacteria }\end{array}$ \\
\hline Day V - Ward & $\begin{array}{c}\text { Gram negative bacilli, gram positive } \\
\text { cocci }\end{array}$ & No growth & $\begin{array}{c}\text { Yersenia.sps, } \\
\text { Staphylococci.sps, }\end{array}$ \\
\hline
\end{tabular}

Table 21: Day V - Evening - Potato Dextrose plates

\begin{tabular}{|c|c|c|c|}
\hline Day & Before Dhupana -4.20Pm & After Dhupana-4.40Pm \& 4.50Pm & Micro organism \\
\hline Day V - Entrance & Growth seen & No growth & $\begin{array}{c}\text { Penicillium.sps } \\
\text { Aspergillus.nigar, }\end{array}$ \\
\hline Day V- Corridor & Growth seen & No growth & $\begin{array}{c}\text { Aspergillusnigar, } \\
\text { Rhizopus.sps, } \\
\end{array}$ \\
& & & $\begin{array}{c}\text { Mucor.sps } \\
\text { Cladosporium.sps }\end{array}$ \\
\hline Day V-Ward & Growth seen & & $\begin{array}{c}\text { Penicillum.sps, } \\
\text { Alternaria.sps }\end{array}$ \\
\hline
\end{tabular}

\section{RESULT AND DISCUSSION}

Before using dhupana, the air sample of the room contained fungi and Bacterial growth. The same room was treated with herbal fumigation that contain anti microbial essential oils possessing Flavonoids, Alkaloids, Steroids, Tannin, Coumarins, Phenol and Quinone. And second air sample was collected after fumigation. The second sample did not find growth after treated with dhupana except in $4^{\text {th }}$ day morning sample, fifth day morning and evening sample. This shows herbal fumigation made of above mentioned drugs acts as germicidal for fungus, gram positive and gram negative bacteria. Regular use of this combination as fumigation in clinics, office, bedroom, living room, kitchen or any indoor working area may cause sterilization effect and disinfect the room. Fumes from above Herbal combinations have not reported irritation, respiratory distress, headache or any discomfort to Human during the study. Growth was found on one sample of fourth day and two samples of fifth day after fumigation. This may be due to contamination during the procedure therefore extreme care should be taken to avoid contamination. Growth may also be due to decreased fume concentration or improper burning of herbal chakrikas and therefore uniform fume concentration has to be maintained, chakrikas must be dry or the herbs must be dry, optimum fire so as to emit fumes has to be maintained otherwise all the active principles would burn before dhupana procedure.

\section{CONCLUSION}

Airborne particles are a major cause of respiratory ailments of humans, causing allergies, asthma, and pathogenic infections of the respiratory tract. Airborne fungal spores are also important agents of plant disease, and the means for dissemination of many common saprophytic fungi. Fumigation is not only essential in Operation Theater or Labour Theater but fumigation is required for entire hospital.

Dhupana or Herbal fumigation with above said Herbal combination are effective against air borne microorganisms. It has showed its antimicrobial property against Bacterial and fungal species. They have been non irritant and did not disturb any individual or any individual's routine activity. There were no adverse reaction to eye, skin, and respiratory system to any 
individual during the procedure. The procedure can be adapted daily and regularly as a healthy practice in the hospital. Thus they can be effective germicidal and safe. The research has to be continued to observe the prolong effect of dhupana and a study has to be taken for number of fumigation needed for one single day.

\section{REFERENCES}

1. Vaidya Yadavji Trikamji Acharya, Charaka Samhitha, Chaukambha Sanskrit Samsthan,Varanasi,4 ${ }^{\text {th }}$ edition,1994,p (162).

2. The Ayurvedic formulary of india. The controller of Publications civil lines Delhi; $1^{\text {st }}$ ed. $4^{\text {th }}$ vol. Part 1. P; 128 129

3. Dr. Gyanendrapandey. Dravyaguna vijnana. Krishnadas academy Varanasi 2002. $2^{\text {nd }}$ ed. P; 127,697, 737.

4. Acharya Vishwanath Dvivedi, Rajanighantu, Krishnadas Academy, Varanasi, ${ }^{\text {st }}$ edition,1982,p (527).

5. Acharya Vishwanath Dvivedi, Rajanighantu,Krishnadas Academy, Varanasi,1st edition,1982,p (552).
6. Priyavarta Sharma, Guru Prasada Sharma, Kaiyadeva Nighantu, Chaukambha Orientalia, Varanasi, Reprint Edition 2009, p.633.

7. Kamat SD. Studies on medicinal plants and drugs in Dhanwantari Nighantu, $1^{\text {st }}$ edition. Delhi: Chaukambha Sanskrit Prathistan.2002; p.20.

8. Golakavasi Lala Shaligramaji Vaisya, Brihatnighantu ratnakara, Mumbai: Khemaraj Srikrishnadas prakashan. p.242.

9. Kenneth. J Ryan. Sherries medical microbiology an introduction to infectious diseases. McGraw hill publication; $1^{\text {sted }}$

10. J.G. Collee. A.G. Fraser. B.P. Marmion. Mackie and McCartney Practical medical microbiology. Elsevier publication; $14^{\text {th }}$ ed

\section{Cite this article as:}

Nisha Kumari, Shashirekha. Antimicrobial action of dhupana (fumigation with herbs) with respect to air borne microbes in indoor environment of central hospital. Int. J. Res. Ayurveda Pharm. Sep - Oct 2016;7(5):48-55 http://dx.doi.org/10.7897/ 2277-4343.075194

\section{Source of support: Funded by Rajiv Gandhi University of health Sciences - Bengaluru, Karnataka, Conflict of interest: None Declared}

Disclaimer: IJRAP is solely owned by Moksha Publishing House - A non-profit publishing house, dedicated to publish quality research, while every effort has been taken to verify the accuracy of the content published in our Journal. IJRAP cannot accept any responsib ility or liability for the site content and articles published. The views expressed in articles by our contributing authors are not necessarily those of IJRAP editor or editorial board members. 